\title{
LA COMUNICACIÓN PERSONALIZADORA EN EL 11-N. UN ANÁLISIS DE CASO EN LA CIRCUNSCRIPCIÓN DE MÁLAGA
}

\section{Personalizating Communication in 11-N. An Analysis of Case in the Circumscription of Malaga}

\section{A comunicação personalizadora no 11-N. Uma análise de caso na circunscrição de Málaga}

COLLADO CAMPAÑA, Francisco. Universidad Pablo de Olavide (España)

fcolcam@upo.es

\section{Fecha de recibido: 10 de febrero de 2015 \\ Fecha de aceptado: 18 de mayo de 2015}

\section{RESUMEN}

El avance de los medios de comunicación y las nuevas tecnologías han llevado a que se hable cada vez más de una "democracia mediática" o "democracia de audiencias". En este sentido, los líderes de los partidos realizan importantes esfuerzos por captar a sus votantes a través de distintos canales y soportes. Esto ha llevado a que los recursos como la tradicional cartelería y el merchandising entre otros cumplan nuevas funciones. Así, el trabajo se centra en estudiar los efectos que persiguen dichos soportes de cara al electorado de los dos partidos más votados (PP y PSOE) en la circunscripción de Málaga en la campaña para las elecciones generales de 2011. Finalmente, se observa cómo estos recursos de marketing político tienen como finalidad principal convertir al líder en una marca, legitimarlo y socializarlo, antes que la búsqueda del voto entre el electorado. De esta forma, la comunicación política se convierte en un instrumento de legitimación de los líderes de los respectivos partidos. 
Palabras clave: merchandising, campaña electoral, marca política, elecciones generales, personalización de la política, candidatos, 2011.

\begin{abstract}
The advance of the mass media and the new technologies has taken that speaks itself increasingly of a "media democracy" or "democracy of targets". In this respect, the leaders of the parties realize important efforts for catching his voters across different channels and supports. This has led that the resources like the traditional printed formats and the merchandising between others fulfill new functions. In this way, the work is focused on studying the effects that chase the above mentioned supports with a view to the electorate of both parties most voted (PP and PSOE) in the circumscription of Malaga in the campaign for the general elections in 2011. Finally, it is observed as these resources of political marketing they have as principal purpose turn the leader into a brand, legitimize and socialize him. So, the political communication is an instrument to legitimate the leaders of the political parties.
\end{abstract}

Keywords: Merchandising, electoral campaign, political brand, general elections, political personalization, candidates, 2011.

\title{
RESUMO
}

O avance dos meios de comunicação e as novas tecnologias têm levado a que se fale cada vez mais de uma "democracia mediática" ou "democracia de audiências". Neste sentido, os líderes dos partidos realizam importantes esforços por captar aos seus votantes através de distintos canais e suportes. Isto tem levado a que os recursos como a tradicional cartelaria e o merchandising entre outros cumpram outras funções. Assim, o trabalho centra-se em estudar os efeitos que perseguem ditos suportes de cara ao eleitorado dos dois partidos mais votados (PP e PSOE) na circunscrição de Málaga na campanha para as eleições gerais de 2011, finalmente, observa-se como estes recursos de marketing político têm como finalidade principal converter ao líder em uma marca, legitimá-lo e socializa-lo, antes que a busca do voto entre o eleitorado. Desta forma, a comunicação política converte-se em um instrumento de legitimação dos líderes dos respetivos partidos.

Palavras-chave: Merchandising, campanha eleitoral, marca política, eleições gerais, personalização da política, candidatos, 2011. 


\section{Introducción}

El análisis de la comunicación de masas y su consolidación como disciplina científica comienza a principios del siglo XX, con los primeros trabajos conductistas de Laswell, Lazarsfeld y Schramm (Sartori, 1992; Vera, 1995). En este contexto, politólogos y comunicólogos descubren la importancia del mensaje, y, por tanto, de las campañas electorales y su planificación para obtener la victoria electoral en la sociedad de masas. Ambas disciplinas inician un camino epistemológico en su intento por analizar los fenómenos de comunicación política como las campañas electorales y la mercadotecnia (Mori, 2011; Swanson y Mancini, 1996; Sartori, 2002; Trejo, 2000). Por lo que, es el inicio de una tensión continua y constante entre el acoplamiento de la comunicación política y las estrategias de marketing que se van influenciando mutuamente a través de sus diversas contribuciones ${ }^{1}$.

En la actualidad, no podemos hablar tanto de una 'comunicación de masas', sino más bien de 'público’2 (Collier y Levitsky, 1997; Milton, 2000; Muñoz-Alonso, 1999). Este concepto de comunicación da consistencia a la perspectiva del diseño de las estrategias electorales, ya que cada partido intenta dirigirse a distintos 'públicos-objetivo' o 'target' para producir los efectos deseados. Estos efectos pueden tener un objetivo táctico (identificar y/o legitimar al líder, vencer en las elecciones, destacar una propuesta estrella del programa, etc.) o un objetivo ideológico (anteponer los valores a los temas, redefinir la ideología, identificación partidista, etc.). La 'comunicación de público' establece una relación directa con lo que algunos autores han denominado una 'democracia de audiencias' (Manin, 1998) o 'democracia mediática' (Muñoz-Alonso, 1999).

El cambio de paradigma de comunicación en los comicios electorales de la democracia es una consecuencia de las transformaciones de los partidos y de los sujetos. Si bien, dichos cambios en las estructuras partidistas son el producto del desarrollo epistemológico en torno a las campañas (Manin, 1998). Ya no existen, partidos de masas, sino más bien 'catch-all-parties' o 'partidos atrápalo-todo' convertidos en empresas de mercadotecnia que venden un producto a una sociedad heterogénea (Kirchheimer, 1980; Panebianco, 2009; Sartori, 2005). En este proceso de transformación de los partidos en grandes agentes socializadores a partidos electorales, se produce la autonomía de la comunicación electoral y la opinión pública como disciplinas (Crouch, 2004). El único interés de los políticos según Crouch es saber qué quiere escuchar la gente y ofrecerle productos que satisfagan dichas demandas. De forma que, los líderes políticos priorizan la búsqueda de apoyo en las agencias de comunicación y grupos de interés y marginan a sus militantes ${ }^{3}$,

1 Estas contribuciones y/o tensiones mutuas entre Ciencia Política y Ciencia de la Comunicación han afectado incluso a la misma organización interna y externa de los partidos. Los partidos tradicionales han dejado de ser actores de socialización para pasar a convertirse en empresas de mercadotécnica política dirigidas a vencer en las elecciones. Por lo que, se observa como esta tensión epistemológica de la Comunicación Política ha tenido unas consecuencias en el ámbito organizativo de las formaciones políticas (Swanson y Mancini, 1996, pp. 11-12).

2 Concepto al que alude Francisco José Llera al referirse a las transformaciones en los condicionantes del mensaje político en la posmodernidad.

3 Como ejemplo actual, se puede observar el ascenso de Podemos en España que ha experimentado el paso desde un partido minoritario hasta adquirir una estructura interna y externa de catch-all-parties. Entre 2014-2015, esta formación ha incorporado temas en su agenda que conectan con distintas demandas presentes en la sociedad española (crisis, servicios públicos, deuda externa, medidas anticorrupción, etc.), ha moderado sus posturas iniciales más radicales y ha eliminado distintos elementos (corrientes 
rompiendo con la tradicional importancia que tuvieron para los partidos cristianos y socialdemócratas hace medio siglo (Thomassen, 2005).

Todo esto, lleva al planteamiento de la posmodernidad, según Crouch (2004), donde lo importante es la venta de ídolos, líderes y propuestas evanescentes con el fin de conseguir la victoria un período tras otro. Mientras a principios del siglo XX, los partidos ofrecían ideologías como respuesta a las expectativas de los votantes y la sociedad de masas asemejaba una suerte de religión con sus propios rituales (Sartori, 1992). En la actualidad, los individuos están fragmentados, y es difícil hablar de comunicación de masas ${ }^{4}$. Por lo que, aumenta la diversidad de colectivos y, por tanto, de audiencias a las que deben llegar los distintos mensajes políticos de un mismo partido.

El diseño de una campaña electoral implica distintos aspectos. Por un lado, la organización de la agenda y de los issues a tratar en la elaboración del programa electoral. Por otro lado, la movilización de recursos humanos como los militantes, grupos de interés y empresas dedicadas a la consultoría política y en comunicación (Panebianco, 2009; Ware, 1996). Además, deben identificarse nítidamente cuáles son los públicos a los que se va a dirigir el mensaje político y basándose en los sondeos previos con el objetivo de rentabilizar aspectos como la volatilidad y evitar la pérdida de votos en relación a partidos con propuestas cercanas. Esta situación lleva a la 'sondocracia', porque los baremos preelectorales son definidores de una realidad virtual, además de un instrumento de posicionamiento de la mercadotecnia (Muñoz-Alonso, 1999).

\section{Marco teórico y preguntas de investigación: personalización y objetivos de los formatos en la comunicación política}

El caso de España ha experimentado un proceso similar al de otras democracias europeas como resultado de esa influencia mutua entre marketing político y organización partidista. Los partidos de masas como eran el Partido Socialista Obrero Español (PSOE) y el Partido Popular (PP) a principios de la Transición, han pasado a convertirse en catch-all-parties durante la década del noventa del siglo pasado (López-Nieto, 1988; Satrustegui, 1992). De esta forma, ambos han abandonado su naturaleza como partidos de clases para convertirse en opciones de gobierno efectivas.

Los principales partidos españoles han abandonado las ideologías puras y han apostado por el tacticismo electoralista debido, entre otros factores, a la influencia de la gran pantalla (Muñoz-Alonso, 1999; Sartori, 2002). Esto ha quedado denominado como la 'glamorización' de la política, por la cual, los contenidos de la comunicación política y los medios se hacen más evanescentes, más líquidos y más moldeables (Trejo, 2000, p. 20). Mientras que, el continente - de forma similar al contenido- se construye de forma favorable a los objetivos que la élite política persigue de cara a su electorado. Por lo que, el mensaje y su formato deben ser simplificados para facilitar su consumo por parte de los electores.

anticapitalistas, animalistas, feministas radicales, etc.) que impedirían su consolidación como una opción de gobierno. Ha transitado desde el radicalismo ideológico hacia el tacticismo electoralista.

4 Recientemente, Steven Lukes ha sostenido que las redes sociales contribuyen a fragmentar a la sociedad en grupos cada vez más reducidos con intereses particulares. Por lo que es difícil encontrar issues o intereses que permitan aglutinar a una gran cantidad de sujetos. 
La simplicidad del mensaje político y la importancia de los líderes y/o candidatos políticos ha llevado al fenómeno que se conoce como la 'personalización' de la política (Caprara, 2007; Dalton y Wattenberg, 2002; Kriesi, 2012). Este fenómeno, en lo que respecta a nuestro interés académico, implica que cada vez más los candidatos: son los protagonistas del espacio público, tienen una mayor visibilidad en los medios que sus propios partidos y pueden llegar a convertirse en marcas electorales. Por lo que, la cuestión para ganar, pasa muchas veces por existir ${ }^{5}$ ante el público y ser aceptado por la audiencia canalizada entre el electorado.

Nuestro marco teórico se fundamenta por tanto en estos tres factores: el carácter estratégico y/o táctico de los catch-all-parties españoles, la simplificación del mensaje en el marketing político y la personalización de la comunicación política. En este sentido y atendiendo al caso español, surge el interés por conocer cuáles son los efectos que la propaganda electoral ha intentado producir en el electorado, o mejor dicho, en la opinión pública (Sartori, 1992).

Según Karvonen (2010), los trabajos sobre personalización de la política pueden dividirse entre: i) los estudios sobre el fenómeno de la 'presidencialización'. ii) Los análisis sobre los efectos de los líderes de los partidos en los comicios electorales. iii) Los estudios eclécticos de distintos enfoques (p. 3). Desde esta clasificación, el presente trabajo puede situarse entre aquellos preocupados por los efectos y/o los objetivos que los líderes articulan a través de dicho fenómeno de personalización.

Por tanto, el objeto de estudio del presente trabajo reside en conocer la intencionalidad y el tipo de respuesta que los partidos políticos esperan obtener en la emisión del mensaje político. Como el mensaje político abarca distintos contenidos y formatos, vamos a centrar nuestro análisis en el estudio de la cartelería ${ }^{6}$ (carteles, fondos de pantalla y merchandising) que los partidos políticos han usado en las elecciones generales de España en 2011 e interpretando sus características desde los presupuestos teóricos de la personalización de la política. Asimismo, se ha seleccionado el estudio de caso en la circunscripción electoral de Málaga ${ }^{7}$, para realizar una investigación intensa y en profundidad frente a otra más extensa y con datos más generalizables.

A partir de aquí planteamos las siguientes preguntas de investigación:

- ¿Cuál es el diseño de los carteles y escenografía de los mítines empleados por los dos partidos mayoritarios en la circunscripción de Málaga durante las elecciones generales de 2011?

- ¿Cuáles son los objetivos que persiguen ${ }^{8}$ cada uno de los soportes estudiados? ¿Existen diferencias o similitudes entre la intencionalidad de un formato y otro?

5 El Centro de Investigaciones Sociológicas en sus preguntas sobre valoración de líderes políticos siempre pregunta al encuestado si conoce o no al líder mencionado. De esta forma, la popularidad es fundamental para triunfar en esta democracia mediática.

6 Término empleado por creativos y diseñadores gráficos para referirse a los distintos soportes de una misma campaña publicitaria o de comunicación institucional.

7 Málaga es una provincia costera de la Comunidad Autónoma de Andalucía. Constituye uno de los principales ejes urbanos de esta región en el conocido triángulo Sevilla-Cádiz-Málaga y su actividad económica está especializada en el sector servicios y turismo. El número de escaños elegidos por esta circunscripción es de 10 parlamentarios para el Congreso de los Diputados.

8 Como el estudio se centra principalmente en los efectos, tarea que suele corresponder generalmente al 'politólogo', según Sartori (1992), no existe una comprobación empírica de si dicha intencionalidad surte efecto en el receptor, sino que lo que nos interesa son los objetivos del emisor en el contexto electoral. 
- ¿Se manifiesta la personalización de la política en estos mensajes y guarda dicho fenómeno alguna relación con los efectos que persiguen estos soportes?

Previamente al trabajo de campo debemos concretar nuestra metodología. Sartori (1992) diferencia claramente la visión del politólogo y del comunicólogo. El primero se centra en cómo la opinión pública supone un elemento de calidad democrática y cuáles son las actitudes de dicho actor a partir del mensaje político. En cambio, el segundo se centra en la fase de producción de traslación de mensaje de un emisor a un receptor. Por tanto, nuestro objetivo no se va a centrar tanto en estudiar las condiciones del acto comunicativo, como sí en poner en relación al mensaje con la influencia y/o los objetivos que el emisor pretende obtener en relación al votante. Así, adoptamos una visión interpretativa y que ponga la intencionalidad del mensaje en relación con los emisores que son los candidatos políticos.

De esta forma, efectuamos un análisis desde la perspectiva politológica, aunque si bien, añadiremos las posibles adiciones que puedan derivarse desde un punto de vista de las Ciencias de la Comunicación. Además, adoptaremos una perspectiva diferenciada en cuanto a la consideración del público como un ente pasivo o activo (Muñoz-Alonso, 1999), sino más bien como un público reactivo que responde ante determinados estímulos o bien los excluye de su proceso de comunicación, evitando así determinadas actitudes previstas. En otras palabras, el ciudadano tiende a seleccionar aquellas informaciones que les son más coherentes y refuerzan sus posiciones. Lo que determina las intencionalidades del emisor en su transmisión del mensaje propagandístico.

Por último, pondremos en relación los análisis acometidos con la normativa que regula las campañas electorales en el aspecto de las fechas y los lugares en los que puede recurrirse al uso de cartelería. De esta forma, pretendemos observar si la personalización de la política tiene algún efecto en relación al cumplimiento de las normas electorales, o si por el contrario, la vulnera.

\section{Metodología}

El mensaje periodístico y el publicitario sufren de un mal común. Este condicionante constante producido por la prevalencia de la imagen sobre la información escrita, es un producto del predominio del medio televisivo sobre el resto (Muñoz-Alonso, 1999). La muestra de elementos de cartelería y escenografía que hemos seleccionado del Partido Popular (PP) y Partido Socialista Obrero Español (PSOE) es la correspondiente a la campaña de las elecciones generales de 2011 y para la circunscripción de Málaga. Se han seleccionado aquellos formatos destinados a crear el 'escenario' en el que se producen los mítines políticos y otros elementos relacionados con dichos contextos de la campaña, como

- Cartel del candidato presidencial.

- Panel o fondo para el mitin de los candidatos.

- Merchandising del partido político (bolígrafos, libretas, obsequios, etc.).

A partir de estos, efectuamos un análisis cualitativo mediante una ficha técnica propia, aplicando una serie de criterios a cada uno (Muñoz-Alonso, 1999; Sartori, 1992; Ware, 1996). Es necesario advertir que la mayor parte de estos contenidos van dirigidos a los votantes fieles y simpatizantes de la fuerza política correspondiente, y 
no tanto a los no identificados9. Para ello, se analizan las siguientes características de dichos elementos propagandísticos, a partir de las recomendaciones efectuadas por los siguientes autores (Goffman, 2006; Peña y Ortiz, 2011; Rodrigo 2013; Sartori, 1992)

- Color: el color ha sido definido como una forma de presentación ante los votantes y para establecer una continuidad en la definición de la marca política. Los colores no son una cuestión baladí en la comunicación política, ya que transmiten sensaciones y tienen una función emotiva.

- Atracción de votantes: sí/no. Aunque los formatos que se analizan van dirigidos a los votantes y simpatizantes que tienen cierta predisposición en su intención de voto, es necesario observar cómo se presentan los candidatos ante dicha audiencia. Especialmente, se observa el lema ${ }^{10}$ o mensaje escrito que acompaña al formato y que busca crear un 'marco' o 'framing' de la realidad.

- Legitimación de la candidatura: la comunicación política ofrece un carácter legitimador en tanto que pretende presentar a los líderes ante la sociedad. En este sentido, la propaganda pretende legitimar la selección de candidatos que ha sido el resultado de una decisión interna del partido y en algunos casos, fruto de unas primarias.

- Ilustración de los candidatos: es interesante observar en qué encuadre aparecen los diputados y candidatos a la Presidencia. Al respecto, recurrimos a la técnica de los planos y la posición en la que aparecen los personajes políticos.

- Contribución a la socialización/identificación política: en las últimas décadas, los partidos han abandonado su función de socialización política. Por lo que, la propaganda debe crear una ilusión visual que acerque los candidatos a sus militantes y electores.

- Efecto-reclamo: algunos soportes y formatos sirven como reclamo, en tanto que esperan una respuesta de los votantes como su adquisición, la identificación o el voto.

- Público objetivo: no identificados, fieles (arribistas o creyentes) o totalidad de votantes. Aunque los carteles y otros soportes van destinados principalmente a movilizar a los identificados, pueden realizar una atracción secundaria hacia los no identificados.

- Ubicación física: estos formatos son colocados en un lugar concreto, lo que tiene un valor y un carácter social. Por eso, se analizará como un dato añadido que ayude a contextualizar el mensaje.

A continuación, efectuamos un estudio pormenorizado de cada uno de estos elementos. Con el objetivo de clarificar su utilidad práctica en la campaña en su intento por 'personalizar' la política.

9 Desde el punto de vista teórico, la importancia de los líderes políticos no ha aumentado con el tiempo, sino que en sistemas parlamentarios siguen primando los partidos como agentes de reclutamiento (Karvonen, 2010). Por lo tanto, vamos a centrarnos en los formatos dirigidos a los votantes y simpatizantes.

10 La teoría del 'framing' o enmarque de la realidad adquiere un papel importante para contextualizar la posición del candidato, sus valores y sus propuestas (Goffman, 2006). Es necesario transmitir a los votantes una interpretación de la realidad y una del sentido producido por el líder (Jiménez, 2008). 


\section{Resultados}

\subsection{La cartelería y el merchandising como recurso propagandístico del Partido Popular}

En el caso del Partido Popular, las elecciones generales de 2011 representan la tercera vez que se presenta Mariano Rajoy Brey como candidato por esta formación. A la par que son unas elecciones adelantadas por el anterior Presidente, José Luis Rodríguez Zapatero (PSOE), coincidiendo con una pérdida de confianza política en su liderazgo ${ }^{11}$ (Jiménez-Díaz y Collado-Campaña, 2014). A lo largo de los últimos años, el liderazgo de Rajoy se había visto cuestionado por distintos adversarios dentro de su partido, principalmente Esperanza Aguirre. Por ello, la cartelería y el merchandising deberían jugar un papel importante para legitimar su imagen de cara a su electorado que había sido puesto en duda, especialmente entre 2008-2009 tras su segunda derrota electoral.

El Partido Popular presenta una serie de soportes en su campaña que mantienen un mínimo común denominador como es el recurso a los colores blanco y azul. Este último, que ha venido siendo uno de los colores tradicionales del partido ${ }^{12}$, perpetúa su continuidad como prueba de ser una de las principales 'marcas políticas' del mercado electoral español. En otras palabras, el mantenimiento de este color es una consecuencia de la naturaleza del PP como 'partido atrápalo-todo' y, por tanto, también lo es de la competencia en las elecciones con las otras fuerzas políticas (Kirchheimer, 1980). En un análisis de los tonos empleados y el mensaje que expresan a sus receptores, el color azul transmite confianza, seriedad y estabilidad asociándose con los valores que defiende la formación, mientras que el blanco manifiesta paz y no confrontación.

En el cartel de campaña (tabla 1, imagen 1.1.), se ha recurrido a la imagen del candidato a la Presidencia, Mariano Rajoy, de forma que se produce una personalización del liderazgo (Martín, 2006) y en un intento por legitimarlo como el candidato más válido. Se ha escogido una posición de busto, por lo que se aumenta la caracterización y fijación en la persona del líder. Este elemento no persigue la búsqueda de votos, ni contribuye a la socialización de los electores de cara a perpetuar su intención de voto u obtenerla de otros indecisos. Su gran finalidad es buscar el consenso en torno al líder político, en un intento por legitimarlo frente a sus opositores internos. Por tanto, su principal utilidad consiste en legitimar su candidatura y presentarlo ante la sociedad, ya que el cartel suele aparecer colgado en distintas paredes, expositores e incluso como banderolas. Por eso, la intención del cartel junto al de los otros partidos tiene sentido en el espacio público donde dirigido a la totalidad de votantes recuerda y alude al momento de la campaña electoral que se está produciendo y que por tanto, realiza una llamada al voto a sus fieles. Su finalidad última consiste en recordar a los identificados que tienen el deber de emitir su voto en las presentes elecciones a través del líder que la marca política -el partido- presenta ante la audiencia.

11 A finales de su mandato en 2011, Rodríguez Zapatero se situaba en la categoría 'ninguna confianza' en los niveles más altos registrados, hasta ese momento, situación que ningún otro Presidente de la democracia española había experimentado.

12 A principios del siglo XX, el Partido Popular había abandonado el uso del naranja por una búsqueda de unos tonos más apagados y menos agresivos, además de evitar colores cálidos que suelen estar asociados con las formaciones de izquierdas. 
En la pantalla o fondo de candidatos (tabla 1, imagen 1.2.), encontramos una caracterización de los cabezas de lista del partido por la circunscripción de Málaga. Por un lado, Celia Villalobos, como número uno para el Congreso, y Francisco de la Torre, como número uno para el Senado, cuyas imágenes aparecen sobre un fondo amarillo para remarcar su condición de candidatos. De hecho, es interesante observar este color, pues representa una excepción a las tonalidades empleadas por esta formación. Por otro lado, los rostros que aparecen junto a los suyos se tratan de cargos burocráticos y locales del partido, que no concurren para las elecciones generales. Los cuatro personajes ilustrados aparecen en una posición de busto, igual que el cartel de Rajoy, y con la técnica del cuarteado ${ }^{13}$ empleada desde el diseño gráfico y que consiste en la simulación de un efecto de colores de forma similar a un cómic. El recurso tiene como objetivo presentar una imagen cercana, joven y desenfadada de los candidatos con el objetivo de romper la posible distancia que pudieran percibir subjetivamente sus votantes ${ }^{14}$.

En cuanto al público objetivo, se dirige a los fieles, ya que esta pantalla se presenta en uno de los mítines de campaña y tiene la finalidad de socializar, o acercar la imagen y las propuestas de los políticos a sus votantes identificados. Además, suponen un intento de legitimación de Mariano Rajoy en tanto que estos líderes locales del partido suscriben su apoyo a dicha candidatura y su integración como parte de la misma por la circunscripción de Málaga junto al apoyo de otros políticos locales. En este sentido, también tienen una intención de atracción de votos en tanto que la gestión realizada por personas como el alcalde de Málaga, Francisco de la Torre, y la diputada y exalcaldesa, Celia Villalobos, se presentan como avales del liderazgo y la autoridad que se le atribuyen al candidato presidencial. Se intentan atraer los votantes populares de la arena local hacia la nacional. Son importantes estos datos, porque suponen una serie de 'valores locales' que se presentan como garantía de la oferta política realizada por Rajoy. Así, se produce una retroalimentación desde la personalización de la política local hacia la personalización de la política nacional. En resumidas cuentas, se presenta la escena del líder nacional que cuenta con el apoyo de sus homólogos subnacionales como respuesta implícita a los momentos de crisis interna de su liderazgo.

En último lugar, los productos de merchandising (tabla 1, imagen 1.3.), tienen una finalidad complementaria en la campaña. Por un lado, legitiman al conjunto de las candidaturas realizadas por el partido, recordando el lema y color. Por otro lado, no producen una socialización, ya que el uso de un bolígrafo o una libreta de una determinada formación no indican necesariamente que se esté de acuerdo o en desacuerdo con ella. Tampoco implica que haya existido un contacto entre los candidatos y los electores, ni la asistencia a una actividad de la agenda de la campaña, como un mitin o un acto oficial. Si bien, cumplen con un efecto reclamo, ya que son objetos gratuitos que se reparten durante la campaña tanto a fieles como no identificados, es ahí donde juega no tanto su intención de búsqueda de voto como de recuerdo del mismo a los que ya tienen dicha decisión tomada con anterioridad. Este recuerdo del voto se efectúa a partir de que los usuarios de estos obsequios los utilicen en su vida diaria (bolígrafos, llaveros, etc.) y recuerden que tienen que votar cada vez que los utiliza

13 El 'cuarteado' es un recurso de filtros que ofrece mayoritariamente el software de imagen Photoshop.

14 Entre los votantes del PP se ha observado un mantenimiento de la confianza por el partido, pero cierto desencanto o baja valoración del líder en los últimos años, según los barómetros políticos del CIS. 


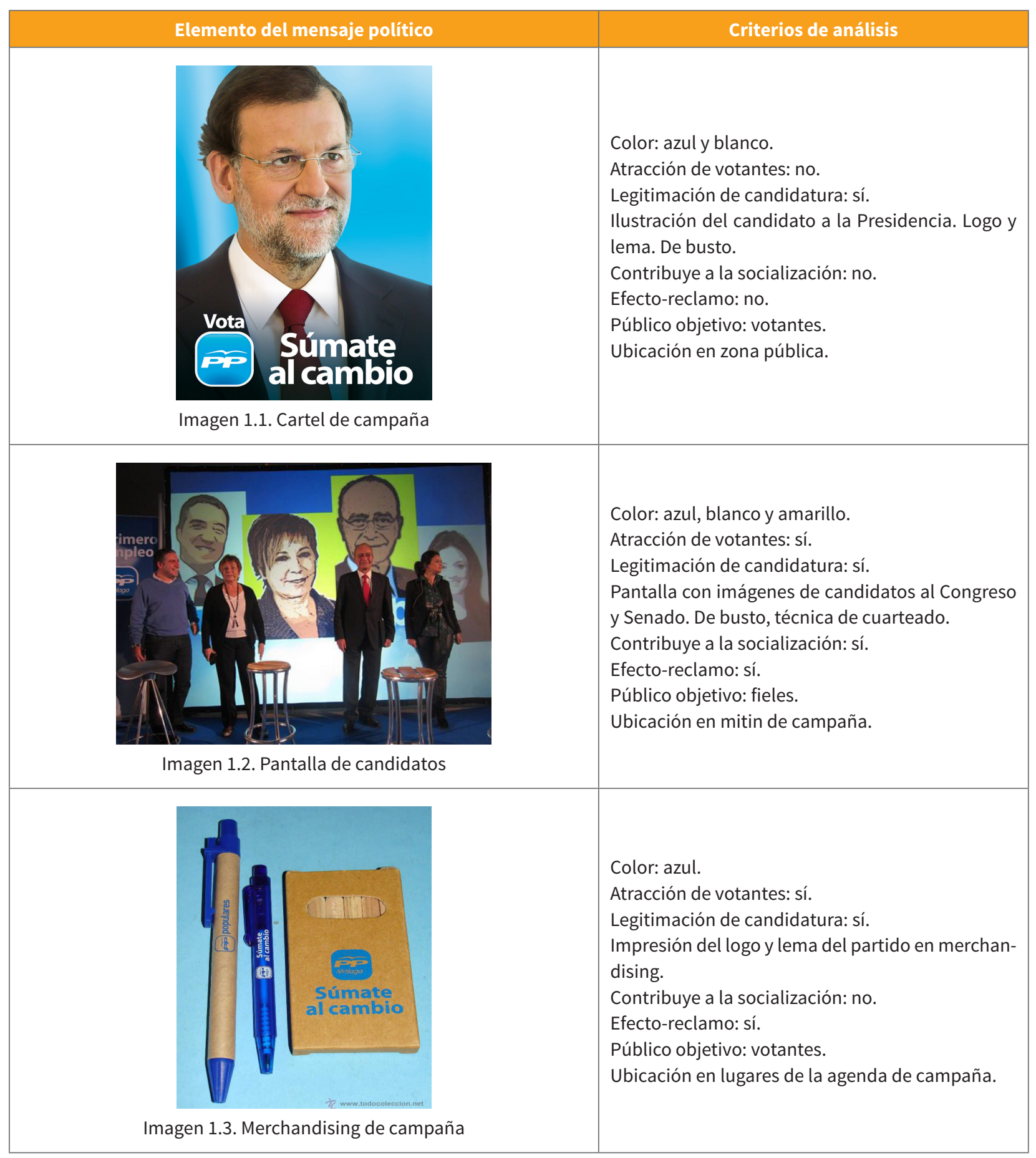

Fuentes: Sur, La Opinión de Málaga y PP-Málaga. 
Es relevante destacar como aquellos formatos no dirigidos a la socialización, comparten como efecto la legitimación de la candidatura y el recuerdo del voto con el lema del partido 'Súmate al cambio'. Este emblema transmite el marco de que el PSOE se ha mantenido durante dos legislaturas en el Gobierno, y que por calidad democrática, es conveniente no solo que gane el PP, sino que se produzca una alternancia en el ejecutivo. Lo cual viene a influir en la decisión de los no identificados, más que en los fieles que lo asimilan más como una postura de calidad democrática que vendría favorecida únicamente por la victoria de su partido.

El 'cambio' referido en el marco que crean estos mensajes políticos no lo es tanto en el líder, como en el partido. Ya que el líder, que es la tercera vez que repite tras dos derrotas, se presenta como una selección u oferta realizada por parte del partido. Posteriormente, a través de la legitimación de dicha selección y la personalización de la campaña en su liderazgo se le añaden determinados políticos locales. Estos políticos locales, a través de los formatos analizados, vienen a ofrecerse como garantes o avalistas de dicha candidatura presidencial con el objeto de sumar sus votantes en el ámbito local a las elecciones generales. De forma que, la socialización de los votantes con estos políticos del ámbito municipa ${ }^{15} \mathrm{y}$ la asunción de distintos objetos de merchandising son el intento por reclamar una respuesta en forma de voto por parte del electorado de esta circunscripción. Finalmente, la principal función del merchandising para el Partido Popular es simplemente la de actuar como recuerdo o activación del voto entre los fidelizados.

\subsection{La cartelería y el merchandising como recurso propagandístico del Partido Socialista Obrero Español}

En el caso del PSOE, se produce una sustitución del líder nacional por un nuevo candidato. El Presidente del Gobierno, José Luis Rodríguez Zapatero, había convocado las elecciones generales de 2011 como un adelanto electoral tras el empeoramiento de la crisis económica. Este candidato que había ganado dos elecciones generales se retiraba debido al desgaste de su confianza, una variable que marcó un record histórico ese mismo año durante su Presidencia (Jiménez-Díaz y Collado-Campaña, 2014). En su lugar, dejaba como continuador a Alfredo Pérez Rubalcaba en un intento por renovar el liderazgo socialista. Rubalcaba había sido hasta esos momentos ministro en el gobierno de Zapatero y también con Felipe González anteriormente. Además, era la primera vez que se presentaba como candidato por el PSOE a la Presidencia del Gobierno en las elecciones generales. Por lo que, era necesario legitimar su candidatura a la Presidencia a través de la campaña electoral en un lapso de tiempo inferior al de Rajoy, quien ya llevaba dos legislaturas como candidato del principal grupo de la oposición.

La marca del candidato y la del partido son los dos ejes vertebradores de la campaña electoral del PSOE. Así, la estrategia repite las líneas y el estilo que ya inició la campaña de Zapatero en 2004, destinada a convertir el candidato en una marca por encima de la del propio partido (Campmany, 2005). Principalmente, a través de una técnica consistente en crear el logo a partir de la primera letra del apellido del candidato. Así, los socialistas utilizaron "Z" de Zapatero en 2008 y "R" de Rubalcaba para las generales de 2011. De hecho, la influencia de la personalización de la política a través del marketing político tiene un mayor peso en este partido si observamos estos antecedentes.

15 Es preciso recordar que el nivel de gobierno municipal es donde se produce una mayor cercanía entre los representantes políticos y la ciudadanía. 
Sin embargo, en el caso de Rubalcaba el marketing político socialista no llega a supeditar la marca del líder frente a la marca de la formación. Un hecho que sí sucedió en las campañas electorales de Zapatero.

El lema de campaña 'Pelea por lo que quieres' es el eje común que comparte tanto la propaganda del PSOE como el merchandising del líder socialista. Los colores blanco y rojo son los empleados por esta formación. Por un lado, el color rojo remite a la ideología de izquierdas y la rebeldía, mientras que el blanco sobre rojo tiende a crear un efecto de realce y que también conecta con el tono de la grafía del logo del partido. De esta forma, se crea un marco de 'resistencia' frente a la victoria que vaticinaban las encuestas tras la pérdida de confianza y el descalabro de los socialistas tras el último año de gobierno de Zapatero.

En primer lugar, el cartel de campaña (tabla 2, imagen 2.1.) ofrece la imagen del líder, Rubalcaba, en plano americano ${ }^{16}$, con el lema de campaña y situado delante de un público de militantes. El cartel, al igual que el de otras formaciones, no contribuye a la socialización, ni genera un efecto reclamo. Al contrario, sus efectos residen en legitimar al nuevo candidato socialista ante su electorado y recordar el momento de campaña en que se encuentra, de cara a mantener la fidelidad de aquellos identificados que ya han decidido previamente su voto a esta opción política. ¿Por qué aparece el candidato delante de un público formado por militantes? Ante la delicada situación que experimentaba el PSOE, la pérdida de intención de voto y el intento de presentar a un nuevo candidato, la finalidad de esta imagen es fundamental. Su objetivo primordial es la legitimación del candidato con respecto a sus votantes, parte de los cuales estaban desencantados tanto con Rubalcaba como con los últimos años de Zapatero. Por lo que, se puede hablar de un primer target que sería la totalidad de los votantes y un segundo más concreto, que son los fieles del partido.

En segundo lugar, el fondo de pantalla usado en la circunscripción de Málaga (tabla 2, imagen 2.2.) presenta una serie de discrepancias en relación con las líneas generales de la campaña. Para empezar, recurre a un juego de figuras cuadradas en distintas tonalidades desde el celeste hasta el azul oscuro. De hecho, aparece, por un lado, duplicado el logo del partido nacional y, por el otro, el del partido en la circunscripción de Málaga. Por esta razón, el color azulado tiene relación con los colores de la ciudad, de impronta costera y marítima. Aunque mantiene los colores de campaña, emplea otros para remarcar la importancia de la formación local del partido. Su función consiste en legitimar a los candidatos y producir socialización política de los candidatos de la circunscripción en su público objetivo. Por otro lado, no se observa la presencia de la marca "R" del candidato, sino principalmente la marca del partido como en el cartel de campaña. Esto probablemente guarde una relación con la organización interna del partido como una estructura de catch-all-party donde lo que prima son las siglas del partido frente a la marca de los candidatos.

En tercer lugar, nos encontramos con la gama de productos de merchandising (tabla 2, imagen 2.3.) que van asociados al candidato y a sus valores, jugando con la primera letra de su apellido. De hecho, estos objetos vienen a aumentar la socialización política a un grado mayor que el merchandising de otros partidos, pues algunos de estos productos estuvieron a la venta ${ }^{17}$ y no solo se repartieron de forma gratuita entre los fieles durante las campañas. En la página web del candidato se podían encontrar tazas, cafeteras, llaveros, colgantes y toda suerte de utensilios que podían comprarse de forma on-line.

16 Figura cortada a ras de las rodillas.

17 A diferencia del merchandising de otros populares, la puesta a la venta de estos productos por parte del PSOE sirve como técnica para valorar el grado de compromiso de los votantes con el líder. 


\section{ESTUDIOS}

Por lo que, estos productos de merchandising juegan un importante efecto-reclamo y vienen a contribuir a la legitimación del candidato y a la socialización política de los fieles con su líder, al adquirir objetos que se identifican con el mismo. Asimismo, vienen a buscar la activación y/o el recuerdo de voto de los socialistas a través de estos objetos - como llaveros o tazas - que debido a su utilidad pueden ser visualizados una o varias veces a lo largo de una jornada por parte de los votantes. El juego con la "R" para destacar valores del candidato (recto, reflexivo, receptivo, etc.) representa un intento por crear un marco del candidato socialista como un líder fresco y novedoso frente a su adversario.

Tabla 2. Cartelería del PSOE-Málaga durante las elecciones generales 2011

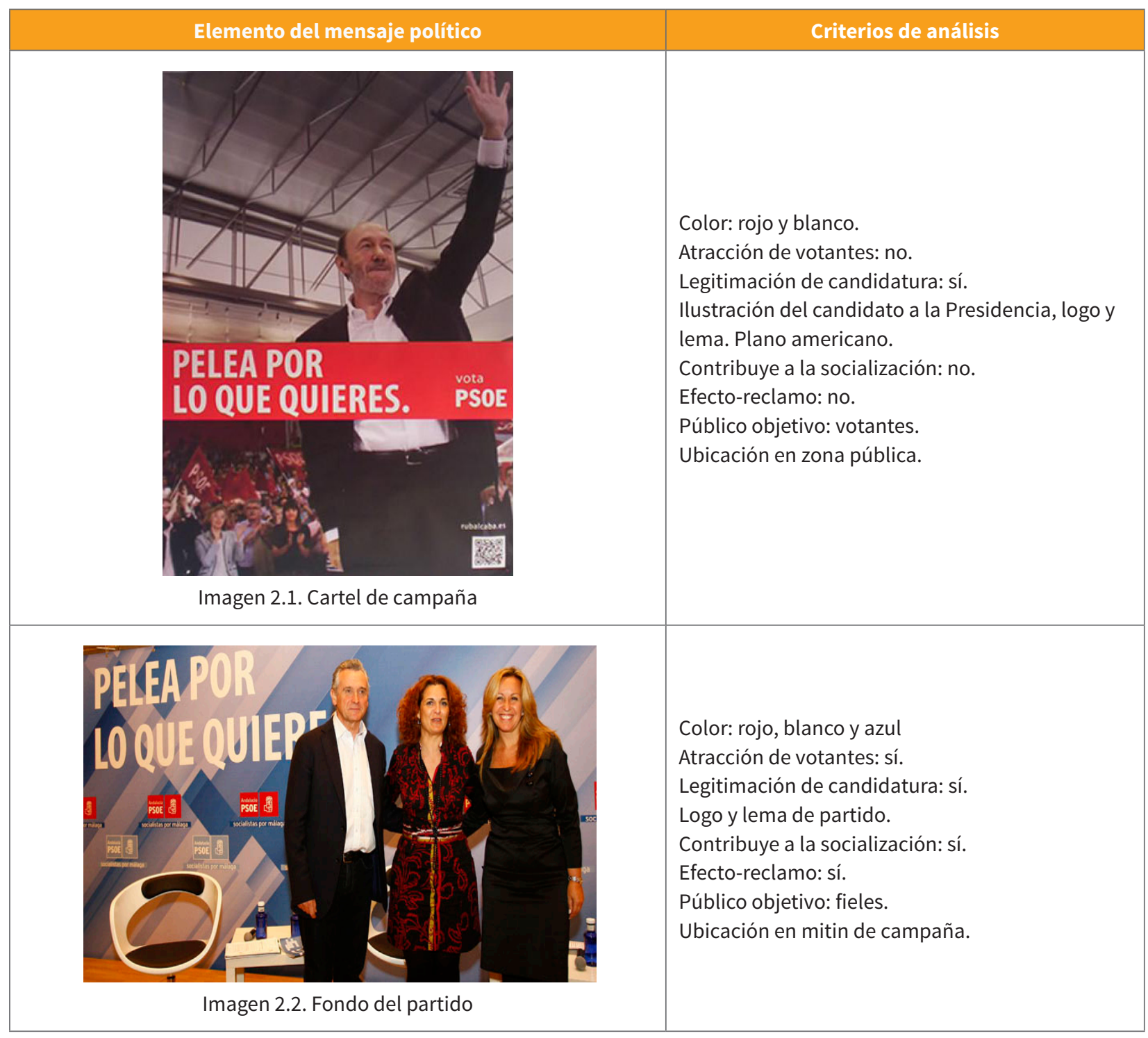




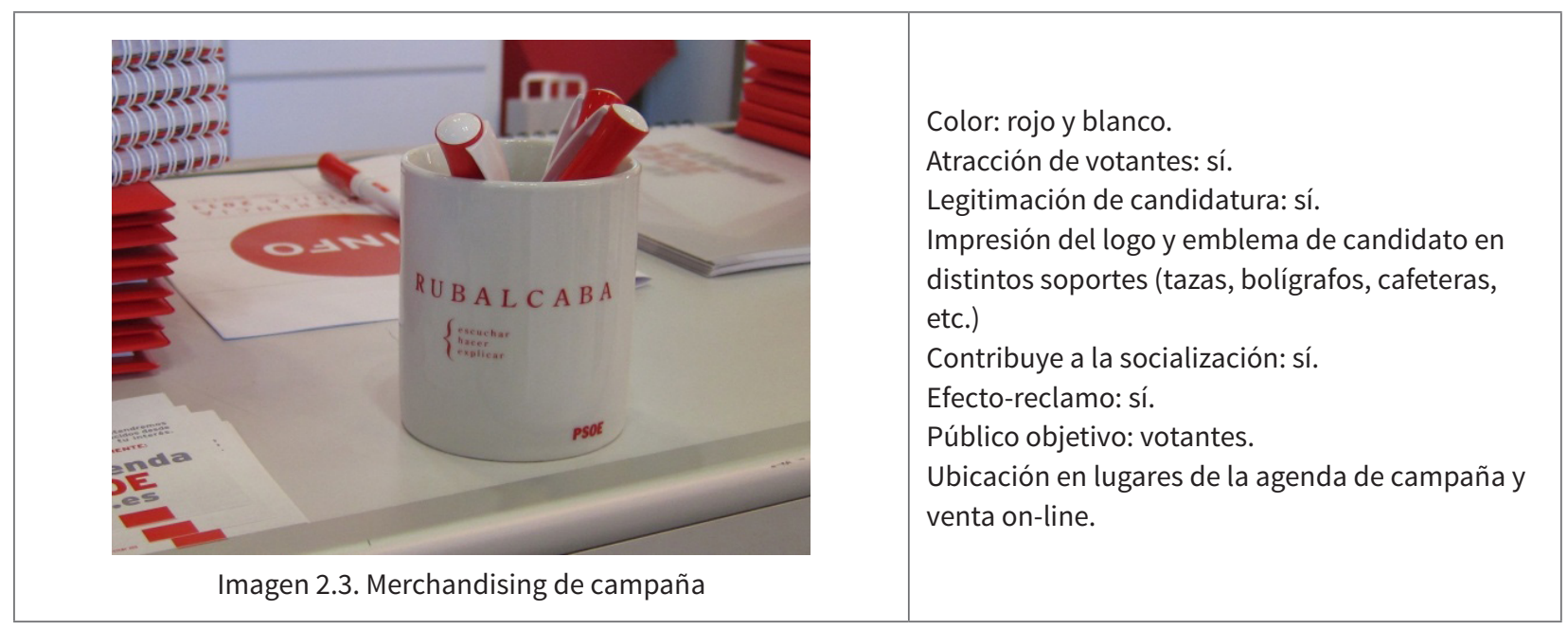

Fuente: Sur, La Opinión de Málaga, PSOE-Málaga y Web del candidato.

En definitiva, el merchandising del PSOE no cumple con una función complementaria, sino que más bien responde a la necesidad de personalizar al líder para crear su marca con nombres y apellidos. Mientras que, el lema 'Pelea por lo que quieres' es un mínimo común que realiza una llamada al voto de los fieles y de los votantes como reclamo para evitar una 'victoria de la derecha'. Cabe también destacar, como la estrategia socialista convierte al partido en una marca y al candidato a la Presidencia también. Esto da como resultado una duplicidad del producto político como consecuencia de los efectos que los medios audiovisuales ejercen sobre la candidatura política a la cual tienden a personalizar (Martín, 2006).

Se observa una tensión esquizofrénica en el marketing. Por ello, conviven por un lado la marca del partido en los carteles y los fondos, pero después se diseña toda una gama de productos de merchandising que juegan con la letra "R" del candidato. ¿A qué se debe esta dualidad entre la marca del líder y la marca del partido? ¿Por qué el grado de personalización de la marca política del líder que se había producido con "Z" de Zapatero en las elecciones generales de 2008 no llega a alcanzarse con la "R" de Rubalcaba en 2011? Para responder a esta pregunta es necesario tener en cuenta dos factores relacionados con el líder y su contexto (Martín Fernández, 2013). En primer lugar, la pérdida de intención de voto que ofrecían las encuestas mostraba una clara derrota de los socialistas. Por ello, la candidatura de Rubalcaba fue ante todo un 'sacrificio' de distintos sectores del PSOE por salvar la situación y desacreditar a uno de los hombres de máxima confianza de la época de Zapatero. En segundo lugar y en relación con lo anterior, los socialistas habían entrado en una crisis interna de liderazgo y la fractura del partido en torno a aquellos más cercanos a Rubalcaba y otros más cercanos a Carme Chacón.

Por lo tanto, la comunicación política del PSOE en la campaña general de 2011 no iba solo destinada a evitar la pérdida de votos, sino que también representaba un intento por afianzar a uno de los líderes dentro de las disputas internas. De forma que, estas tensiones dentro de la estructura interna han tenido sus consecuencias en la mercadotecnia electoral, que no ha llegado a concebir una auténtica personalización y legitimación de Rubalcaba. Como consecuencia y prueba de ello, el líder abandonó el liderazgo de la formación un tiempo más tarde, continuando las luchas interiores a través de diversas elecciones primarias y el surgimiento de nuevos liderazgos. 


\subsection{Comparativa entre los soportes propagandísticos de PP y PSOE}

Las estrategias de campaña de PP y PSOE comparten una serie de elementos comunes, si bien después se producen diferencias que remarcan su carácter y su imagen ante el público. En cuanto a sus similitudes, ambos tienen un lema de campaña que repiten en la mayoría de los soportes propagandísticos. El cartel, tiene como principal objetivo legitimar al candidato y recordar a los identificados que se encuentran en período de campaña. En el caso del candidato popular, Mariano Rajoy, aparece un fondo con un color y la ausencia de otro elemento humano. Esta ausencia de militantes o de otros candidatos políticos tiene como finalidad remarcar su candidatura a la Presidencia y la incuestionabilidad de su liderazgo, tras las disputas que había experimentado con otros dirigentes entre 2008-2009. Ante todo, transmite la sensación de que dicho líder es la selección que ha operado el PP y la que presenta como más óptima ante su electorado. Para los socialistas, la imagen de Rubalcaba junto a una audiencia de militantes en un mitin intenta conciliar las tensiones internas ante su liderazgo. Asimismo, se presenta a la multitud como legitimadora de este candidato, dando la sensación de que cuenta con el apoyo de sus simpatizantes y votantes. No hay duda de que la realidad que se ha mostrado después de los comicios generales de 2011 ha sido distinta, una que dio como resultado la pérdida de liderazgo de Rubalcaba y la continua fragmentación entre los barones socialistas y las distintas corrientes internas ${ }^{18}$.

Los fondos o telones de campaña de ambos partidos tienen finalidades similares que son la activación del voto, la legitimación y la socialización. Sin embargo, recurren a técnicas distintas y, por tanto, legitima y socializa a agentes distintos. En el caso de los populares, no se presenta la marca del partido, sino que se presenta la marca de los candidatos de la circunscripción y se personalizan. De esta forma, la gestión de estos candidatos que han sido alcaldes, se presenta como una garantía que apoya y confía en el candidato presidencial. Se intenta aprovechar esa legitimidad y socialización de estos políticos locales en beneficio de la legitimidad y el acercamiento de la figura de Mariano Rajoy. En el caso de los socialistas, se evita la aparición de la marca personal del candidato y se otorga más peso a la socialización de los candidatos locales que aparecen investidos bajo la marca del mismo partido. Por lo que, este formato es a la vez una causa y una consecuencia de las luchas internas que en esos momentos mantenía esta formación política.

El merchandising de ambos viene a promover el recuerdo de voto mediante un efecto-reclamo y la legitimación del candidato con sus militantes. Si bien, desde el punto de vista del marketing, más que la socialización, los productos de merchandising buscan la fidelización con una marca política (Sartori, 1992), ya que son productos asimilados antes por los auténticos creyentes que por los responsables de la campaña. Es destacable como el merchandising del PSOE busca socializar a sus electores con el candidato a través de la marca personal del mismo. Lo que no se produce en el caso de los populares.

En una comparación global, los diversos matices marcan la distinta imagen que quieren proyectar al público. Por su parte, el PP tiende a imponer los colores azul y blanco como mínimo común de todos sus soportes y en

18 En verano de 2014, Alfredo Pérez Rubalcaba celebró primarias internas para la designación de una nueva ejecutiva dentro del PSOE y su reemplazo. Entre los líderes que se presentaron para tomar el relevo se encontraban Pedro Sánchez Pérez-Castejón, Eduardo Madina Muñoz y José Antonio Pérez Tapias. Finalmente, la confrontación acabó con la victoria del primero y su compleja situación como líder socialista en un partido fracturado en diversos sectores. 
el cartel solo se presenta al candidato a la Presidencia. Asimismo, uniformiza el lema para todos los soportes, sirviendo de emblema y/o uniforme. Por lo que, solo los fondos de campaña en los mítines locales, se desvían al presentar la imagen de los candidatos locales y los cabezas de lista. Así, se denota una candidatura de corte presidencialista y jerárquico, aunque cabe la posibilidad de poner cara a los segundos de a bordo, es decir, a los diputados de la circunscripción.

Por otro lado, el PSOE solo muestra en su cartel y en sus soportes la imagen del candidato a la Presidencia. Lo que tiene una relación con la duplicidad de marcas: la del partido y la del líder. De forma que, no se permite la aparición en los formatos de otros candidatos para mantener la primacía de las marcas del partido y de Rubalcaba. No obstante, sí se otorga cierto margen a diferenciar la marca del partido nacional con la de su homónimo local, permitiendo una diferenciación de colores (azul de la ciudad) y del logo (blanco para el comité provincial). Así, esta matización permite otorgar personalidad al comité provincial, pero a costa de no personalizar a los candidatos por dicha circunscripción. Es paradigmático el caso socialista, ya que esa dualidad de marcas que se observa en sus soportes propagandísticos es una muestra de las disensiones y el malestar interno del partido. Se personaliza políticamente al candidato, pero esa personalización no llega a apropiarse del partido como había hecho su antecesor Rodríguez Zapatero en las elecciones generales de 2008.

\subsection{Cumplimiento de la normativa electoral}

En cuanto al cumplimiento de la normativa, Ley Orgánica 5/1985 de Régimen Electoral General (LOREG), en la sección V se muestran las normas para el desarrollo de los contenidos y mensajes de propaganda electoral. Al respecto, se producen una serie de situaciones que vamos a enunciar a continuación:

- La colocación de los carteles debe realizarse en los espacios establecidos para dicho efecto por los ayuntamientos y otros tablones publicitarios. Si bien, en la práctica, los carteles aparecen colocados en otro tipo de lugares como paredes de casas abandonadas, puentes y otras obras públicas y calles poco concurridas.

- Aunque los consistorios tienen la obligación de proporcionar espacios para la campaña, el PP recurre más al empleo del Palacio de Ferias y Exposiciones (de competencia municipal), mientras que PSOE tiende a realizarlos en su sede local y en hoteles de alta gama de la ciudad.

- En la práctica, el problema reside en la gestión municipal que se efectúa de los espacios para la realización de actos de campaña y el cumplimiento más o menos estricto de la normativa de colocación de carteles.

- Hay que destacar como el merchandising, especialmente aquel destinado a la fidelización con el candidato y que puede adquirirse por Internet, es un formato que escapa a los tiempos de campaña al ponerse mucho antes en venta y por no estar sujeto a un control de la LOREG. Por lo que su venta se regularía más por las normas destinadas al comercio electrónico.

De estas cuestiones extraemos como debate dos aspectos. Primero, cabe preguntarse cómo el partido gobernante, el Partido Popular, en el consistorio gestiona los edificios municipales para los actos de campaña y hasta qué punto la oposición local tiende a buscar otros enclaves. Segundo, surge un debate interesante sobre si el merchandising político debe regularse por las normas electorales, estando actualmente en un estado de alegalidad, o 
debe regirse por la normativa de comercio telemático. Lo que permite la presencia de soportes propagandísticos mucho antes de que comience el momento de campaña electoral definido en la ley orgánica.

En este sentido, el fenómeno de personalización de la política unida al impacto de Internet lleva a nuevas situaciones que no estaban contempladas en la ley electoral. Por lo que, se hace necesaria la creación de nuevas normas que permitan regular estos fenómenos que se producen en la actualidad. De esta forma, se observa como la personalización de la política es un elemento de las campañas electorales que permite a los partidos salvar las limitaciones impuestas por el ordenamiento vigente.

\section{Conclusiones}

Los resultados del presente trabajo de investigación muestran aspectos interesantes que deben ser tenidos en cuenta en el análisis de los formatos de campaña. En un principio, la personalización del liderazgo por los medios audiovisuales es algo común en los partidos analizados (Martín, 2006). Mientras, el PP impone en el cartel a su candidato a la Presidencia y permite cierto protagonismo de los cabezas de lista, el PSOE tiende a convertir a su líder en una marca comercial con cierta independencia del partido, siguiendo la trayectoria que dibujó Zapatero en las generales de 2004 (Campmany, 2005).

Tanto entre los populares como entre los socialistas, el objetivo del cartel principalmente es la legitimación del candidato presidencial y movilizar el voto de los identificados en un contexto complejo. Ambos líderes, aunque experimentaban situaciones distintas se encontraban en un momento en el que su liderazgo había sido puesto en duda. En el caso de Mariano Rajoy, se había cuestionado su papel como líder tras la segunda derrota en 2008 por parte de Esperanza Aguirre; además, uno de sus barones regionales, Francisco Álvarez Cascos, se había separado del partido, creando uno propio. En el caso de Alfredo Pérez Rubalcaba, algunos miembros como Carme Chacón y Eduardo Madina habían criticado en distintas declaraciones su liderazgo. A la par que, había formado parte del Gobierno de Rodríguez Zapatero que había tenido que adelantar las elecciones debido a la difícil crisis económica. Por último, ambos partidos atravesaban (y atraviesan en la actualidad) distintos escándalos de corrupción política.

Los fondos de pantalla buscan como objetivo acercar o socializar a los votantes con los candidatos de la circunscripción local estudiada y legitimar la candidatura en ambas formaciones. Si bien, deben señalarse diferencias sustanciales como la aparición de los rostros de los candidatos locales en el PP de forma que intentan presentarse como un aval del líder del partido, ya que estos candidatos han sido y son representantes políticos en el ámbito municipal. Entre los socialistas, se opta simplemente por un fondo donde está presente la marca del partido, pero no en cambio la marca del líder. Por lo que, transmite una imagen de la disensión y la falta de acuerdo de los socialistas en torno a Rubalcaba.

Para el merchandising se ha advertido principalmente como finalidad el efecto-reclamo al entregar objetos que puedan ser utilizados en la vida cotidiana y faciliten el recuerdo de voto entre los identificados. Si bien, en el caso del PSOE, se crea toda una gama de productos con la marca del líder en un intento de adquirir una función socializadora en un momento en el que es cuestionado y experimenta una pérdida de intención de votos. Entre los populares se recurre simplemente al lema de la campaña y el logo del partido.

El mínimo común denominador de los formatos empleados pasa por la legitimación de los candidatos. Lo cual, indirectamente, podría llevarnos a la pregunta de si existe una necesidad de justificar al candidato, que se 
entroncaría con la falta de democracia interna en los partidos analizados y la tiranía de la 'ley de hierro' (Michels, 2008). Por un lado, el PP ostenta un estatuto de corte presidencialista, donde no existe una elección directa de sus candidatos por los militantes. Mientras que el PSOE, aumenta la intensidad de dichos formatos, llegando a hacer una marca del líder, para legitimarlo frente a la controversia entre los militantes que surgió a raíz de las primarias en las que salió electo Rubalcaba.

Esto nos lleva a que la personalización de la política no tiene un efecto destacable en el voto frente a otros factores como los temas políticos o los cleveages (Karvonen, 2010; Thomassen, 2005). Sin embargo, sí tiene una necesidad o es una expresión de la legitimación de los líderes y de su acercamiento al electorado. Al respecto, las tensiones internas entre la marca del partido y la marca del líder que se observa en el caso de Rubalcaba pueden ser demostrativas de esta afirmación. El líder tenía problemas de legitimidad ya que era la primera vez que se presentaba a unas elecciones, existía un desencanto hacia su figura y una pérdida de votos debido a la caída de la confianza en Rodríguez Zapatero. De hecho, Rubalcaba en 2011 no llegó a adquirir el grado de personalización, en términos cuantitativos y cualitativos, que había experimentado el PSOE de Zapatero en la campaña electoral de 2008.

A la luz de estas conclusiones, la personalización política unida a la propaganda electoral cumple con una función legitimadora y socializadora en detrimento de los cambios de funciones de los partidos (Ware, 1996). Antes los partidos de masas tenían entre sus objetivos: la atracción de militantes, su socialización política y la legitimación de los líderes. Ahora en los partidos 'atrápalo-todo' son el marketing político y la mercadotecnia los responsables de acometer con estas funciones, como demuestra este trabajo y cumpliéndose en el mismo las tesis de distintos autores (Crouch, 2004; Manin, 1998; Muñoz-Alonso, 1999). Lo que tiene una analogía con los cambios producidos en los agentes socializadores, que si bien antes lo eran la escuela y la familia, ahora está más que nada en manos de los medios de comunicación y los soportes publicitarios.

Si bien, hay que apuntar una última cuestión, y es que la dinámica interna de los partidos tiene unos efectos en el marketing político. La comunicación política no es solo un instrumento para vencer en las campañas, sino que es un medio de comunicación interna. Como instrumento de comunicación interna está disponible para resolver discrepancias, luchas o problemas de liderazgo. Cuestiones que en el pasado habrían sido resueltas por la organización partidista.

\section{Referencias}

1. Campmany, J. (2005). El efecto ZP. Barcelona: Planeta.

2. Caprara, G. (2007). The personalization of modern politics. European Review, 15(2), 151-164.

3. Collier, D. y S. Levitsky (1997). Democracy with adjectives: Conceptual innovation in comparative research. World Politics, 49(3), 430-451.

4. Crouch, C. (2004). Posdemocracia. Madrid: Taurus.

5. Dalton, R. \& Wattenberg, M.P. (2002). Parties without partisans: Political change in advanced industrial democracies. Oxford: Oxford University Press.

6. Goffman, E. (2006). Frame Analysis: Los marcos de la experiencia. Madrid: CIS.

7. Jiménez-Díaz, J. \& Collado-Campaña, F. (2014). La confianza ciudadana en los Presidentes del Gobierno españoles entre 1986 y 2014. Ponencia presentada en el III Congreso Internacional en Comunicación Política 
y Estrategias de Campaña: marketing político, estrategias globales en escenarios locales y regionales. Asociación Latinoamericana de Investigadores en Campañas Electorales, Santiago de Compostela.

8. Jiménez-Díaz, J. (2008). Enfoque sociológico para el estudio del liderazgo político. Barataria, Revista Castellano-Manchega de Ciencias Sociales, 9, 189-203.

9. Karvonen, L. (2010). The Personalization of Politics. A study of Parliamentary Democracies. Wivenhoe Park: ECPR Press.

10. Kirchheimer, O. (1980). El camino hacia el partido de todo el mundo. En K. Lenk y F. Neuman (Eds.). Teoría y Sociología críticas de los partidos políticos. (pp. 328-347). Barcelona: Anagrama.

11. Kriesi, H. (2012). Personalization of National Election Campaigns. Party Politics, 18(6), 825-244.

12. López-Nieto, L. (1998). Alianza popular: estructura y evolución electoral de un partido conservador. Madrid: CIS.

13. Manin, B. (1998). Los principios del gobierno representativo. Madrid: Alianza.

14. Martín, L. (2006). Elecciones y medios de comunicación: el ser y el deber. En J. Molins y P. Oñate (Eds.). Elecciones y comportamiento electoral en la España multinivel. (pp. 223-239). Madrid: CIS.

15. Martín Fernández, A. (2013). Se llamaba Alfredo. Barcelona: Laertes.

16. Michels, R. (2008). Los partidos políticos. Buenos Aires: Amorrortu.

17. Milton, A. (2000). The Rational Politician. Exploiting the Media in New Democracies. Aldershot: Ashgate.

18. Mori, L. (2011). Il marketing politico e il consenso in democrazia. Iride, 3, 563-574.

19. Muñoz-Alonso, A. (1999). La democracia mediática. En A. Muñoz-Alonso y J.I. Rospir (Eds.). Democracia mediática y campañas electorales. (pp. 13-53) Barcelona: Ariel.

20. Panebianco, A. (2009). Modelos de partido: organización y poder en los partidos políticos. Madrid: Alianza.

21. Peña, P. y Ortiz, A. (2011). El eslogan político español en la campaña de elecciones generales de 2008. Estudios sobre el mensaje periodístico, 17(2), 549-568.

22. Rodrigo, I. (2013). Arte, creatividad y propaganda: el cartel político en España como transmisor de ideología. Creatividad y sociedad: revista de la Asociación para la Creatividad, 20, 1-42.

23. Sartori, G. (2005). Partidos y sistemas de partidos. Madrid: Alianza.

24. Sartori, G. (2002). Homo videns: la sociedad teledirigida. Madrid: Taurus.

25. Sartori, G. (1992). Opinión pública. En G. Sartori. Elementos de Teoría política. (pp. 149-175). Madrid: Alianza.

26. Satrustegui, M. (1992). PSOE: A New Catch-all Party. En G. Colomé (Ed.). Socialist Parties in Europe I: Of Class, Populars, Catch-all? Barcelona: IPS.

27. Swanson, D. y Mancini, P. (1996). Politics, Media and Modern Democracy: an International Study of Innovations in Electoral Campaigning and Their Consequences. (pp. 1-26). Westport: Praeger.

28. Thomassen, J. (2005). Introduction. En J. Thomassen (Ed.). The European voter. (pp. 1-22). Oxford: Oxford University Press.

29. Trejo, R. (2000). El imperio del marketing político. Cuando las imágenes desplazan a las ideas. América Latina Hoy, 25, 15-22.

30. Vera, M. (1995). La teoría de la comunicación: perspectivas para un debate interdisciplinario. Málaga: Universidad de Málaga.

31. Ware, A. (1996). Partidos políticos y sistemas de partidos. Madrid: Istmo. 